\title{
Residual Stress and Contact Force Study for Deep Cold Rolling of Aero-engine Material
}

\author{
Arvind Prithiviraj ${ }^{\mathrm{a}}$, Wang Wei ${ }^{\mathrm{b}}$ \\ Advanced Remanufacturing and Technology Centre (ARTC), Agency for Science, Technology \\ and Research (A*STAR), 3 Cleantech Loop, \#01-01, CleanTech Two, Singapore 637143 \\ aarvindp@artc.a-star.edu.sg
}

Keywords: Residual Stress, XRD, Deep Rolling, Burnishing, Mechanical Surface Treatment, IN718

\begin{abstract}
Deep Cold Rolling (DCR) process is used in various industries to improve the fatigue life of metallic parts by introducing work hardening, deep layer of compressive residual stresses and polished surface finish. In this paper, the influences of the angled design for a hydrostatic tool and its indentation depth to impart compressive residual stresses are studied and compared to its straight tool counterpart for treatment of IN718 material. Residual stress depth profile measurements, using the XRD technique, were employed to determine differences caused by using the angled and straight tool design. Higher rolling forces are measured in an angled tool design with a high indentation depth as compared to a straight tool design caused by the slip stick effect on the internal parts of the tool. This leads to high plastic deformation in the test material significantly affecting the compressive residual stress depth profile depending on its exisiting state.
\end{abstract}

\section{Introduction}

Aero engine metallic parts experience high levels of mechanical and thermal loading, high and low cycle fatigue and foreign object damage (FOD)[1] in service that can lead to early retirement. Suitable mechanical surface treatments applied onto aero engine metallic parts can prolong fatigue life, improve wear resistance and avoid stress corrosion by introducing work hardening, deep compressive residual stresses and polished surface finish[1,2].

Commonly used mechanical surface treatments in the aero engine manufacturing industry are shot peening (SP) and laser shock peening (LSP). Deep cold rolling (DCR), another mechanical surface treatment, uses a rolling ball element that is pressed at high pressure against a metallic part to impart a deep layer of compressive residual stress. Its process parameters that significantly affect the mechanical properties are hydrostatic pressure, rolling tool, contact angle of the tool, stepover, feed rate, yield strength and geometry of the material[6,7]. DCR is a cost effective localised treatment process that can be easily integrated to a robot arm or CNC platform. SP and DCR, are capable of generating high dislocation densities in the near surface regions that inhibit crack initiation although the residual stresses tend to relax faster when the part experiences high temperatures[1,3,4,5]. Deep compressive residual stresses are achieved through LSP and DCR, which help to arrest the crack during the crack propagation stage after FOD impacts and corrosion damages[1,2]. The ability of DCR to generate high cold work at the near surface as well deep compressive residual stresses makes it a good choice for mechanical surface treatment. DCR creates a nanocrystalline surface layer in the range of $3 \mu \mathrm{m}[4]$. The nanocrystalline structure acts as a good resistance to fatigue crack initiation up to a moderate temperature but deteriorates the creep resistance at elevated temperature[4].

The magnitude of the rolling force applied on to the part is a combined effect of the hydrostatic pressure, ball diameter and contact angle of the tool and the part geometry. Higher rolling force imparts the maximum and deeper layer of compressive residual stresses. When the part has reached its work hardened state, the high rolling forces will shift the maximum compressive stresses deeper in the material's depth thereby reducing the compressive stress state at the surface $[1,2,7,8,9]$. Severe

(c) (1) Content from this work may be used under the terms of the Creative Commons Attribution 3.0 license. Any further distribution of this work must maintain attribution to the author(s) and the title of the work, journal citation and DOI. Published under license by Materials Research Forum LLC. 
rolling on a work hardened material will cause tensile stress state at the surface, which is called near surface work softening[2] or cycle softening[1], resulting in a negative effect of decline in hardness and fatigue life and poor surface finish. The factors affecting severe rolling are high rolling force, lower step over value and number of treatment passes[7,8].

The angled tool design is suitable for a curved geometry if the available platform is 3 -axis CNC and a complex internal geometry using multi axis $\mathrm{CNC}$ and robot. However, during the process application development stage, when the component geometry is unknown or due to the platform limitations, DCR tool design is not considered. In this paper, the influences of the angled design for a hydrostatic tool and its indentation depth to impart compressive residual stresses are studied and compared to its straight tool counterpart for treatment of IN718 material. Residual stress depth profiles are measured by XRD technique.

\section{Experiment and Measurement Procedures}

Process Platform Selection and Experiment Plan. The DCR process is integrated with a robot (ABB model no. 6660), which is robust and suitable to handle high process forces. The DCR tool used in the experiment is a hydrostatic single ball point tool with a burnishing ball diameter $\varnothing 6.3 \mathrm{~mm}$ from Ecoroll AG Werkzeugtechnik. Two variants of the hydrostatic tool were used, straight and angled design as shown in Fig. 1. The angled design is indexed to $15 \mathrm{deg}$ so that its burnishing ball element is normal to surface when used in the experiments. A hydraulic pump unit supplies pressurised coolant in the range of 50 to 400 bar to the tool, thereby activating its constant stroke length of $6 \mathrm{~mm}$. The burnishing ball element is made of Tungsten Carbide, which has a higher bulk modulus than the IN718 specimens. The IN718 test material is machined into flat specimens of dimensions $80 \mathrm{~mm}(\mathrm{~L})$ X $20 \mathrm{~mm}(\mathrm{~W})$ X $10 \mathrm{~mm}(\mathrm{H})$. The test specimens are annealed first to relieve the stress.
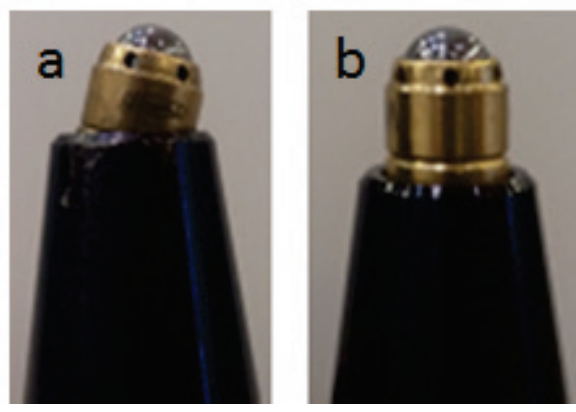

Fig. 1 Single point tool angled variant (a) straight variant (b)

The first experiment set is the track width trials in which track lines caused by plastic deformation for various pressure settings, tool indentation depth and tool design are drawn on the IN718 test piece. The step over, the distance between the subsequent track line in a surface area treatment for a required overlap, is calculated from the track width data.

Table 1 DCR process factors and the selected levels for the $1^{\text {st }}$ and $2^{\text {nd }}$ experiment sets.

\begin{tabular}{|l|l|l|}
\hline Process Factors & $\mathbf{1}^{\text {st }}$ Experiment Set Levels & $\mathbf{2}^{\text {nd }}$ Experiment Set Levels \\
\hline Pressure [bar] & $100,200,300,400$ & 200,400 \\
\hline $\begin{array}{l}\text { Indentation Depth } \\
{[\mathrm{mm}]}\end{array}$ & $2,3,4$ & 2,4 \\
\hline Tool Design & Straight, Angled & Straight, Angled \\
\hline Feed Rate [mm/min] & 1000 & 1000 \\
\hline
\end{tabular}

The second experiment set is for the surface area treatment on the IN718 test pieces for various pressure settings, tool indentation depth and tool type. A zig zag tool path was adopted for the trials. 


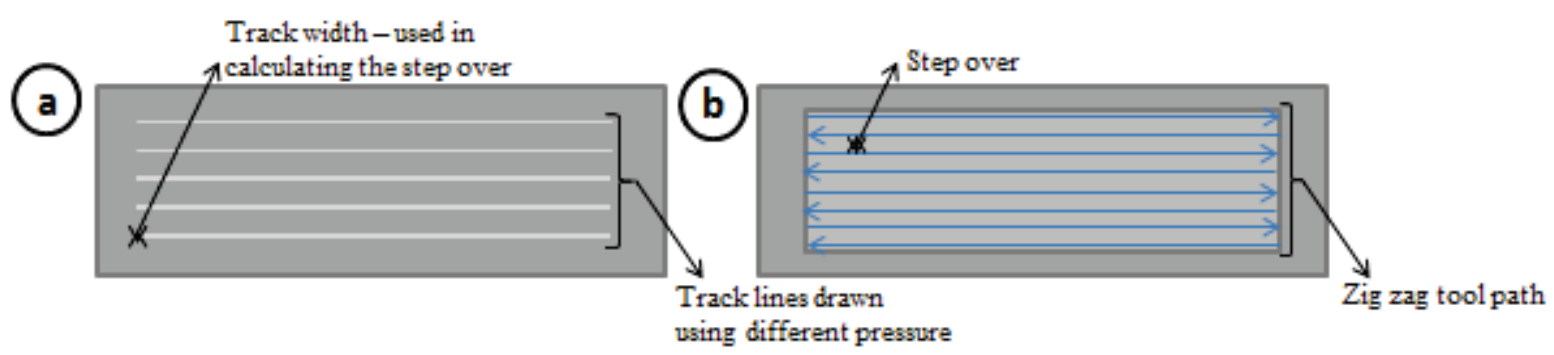

Fig. 2 Illustration of track width in set l(a) and surface area treatment using zig zap tool path in set 2(b)

Track Width Measurement. The track width is measured in microscopic images of treated test pieces captured using Zeiss Stemi 2000 and is used to determine the step over value for a required overlap of $90 \%$.

Rolling Force Measurement. The rolling forces in three directions are measured online during the track width trials with a Kistler dynamometer type 9129AA, which is fixed underneath the processed IN718 test specimen.

Surface Roughness Measurement. The surface roughness is measured using the Taylor Hobson Talysurf stylus profilometer and the measurements are taken in longitudinal (along the rolling) and transverse (perpendicular the rolling) directions.

Residual Stress Measurement. The residual stresses are measured using Stresstech's Xstress 3000 G3R X-ray Diffraction (XRD) in longitudinal and transverse directions. The measurement mode is modified- $\chi$ using two detectors with the $2 \Theta$ angle set at $156^{\circ}$ and the residual stresses are calculated using the $\sin ^{2} \psi$ method. The elastic constants for IN718 were Young's modulus $=207.6$ $\mathrm{GPa}$ and Poisson's ratio $=0.29$

Layer removal at the measurement location for the subsurface residual stress measurement is by electrochemical polishing, using a mixture of perchoric acid and methanol. There is no additional stress induced due to the layer removal by electrochemical means, but stress relaxation occurs resulting in redistribution and are corrected using a standard Moore \& Evans method[10]. The layer removal and the subsequent residual stress measurements are carried out up to the depth of $200 \mu \mathrm{m}$.

\section{Results and Discussions}

The averaged normal direction rolling force is the force acting downward on the test material and it is averaged for the distance of the track width line and the measurements are shown in Fig. 3a. The pressure has an obvious dominance on the rolling force because it increases the contact area of the burnishing ball on the test material. The increase in rolling force remains constant for the straight tool design with varied indentation depth while higher force is measured in the angled tool design as a result of slip stick effect due to the inner sealing and other internal parts that are sliding over each other in the tool.

In the track width comparison plot shown in Fig. 3b, the track width is increased by the pressure causing the burnishing ball to indent deeper in the test material. The track width of the angled tool design is higher compared to the straight tool design; this is because of the higher force in the angled tool. The stability of the angled tool is increased by the indentation depth resulting is higher track width while the straight tool design is stable throughout. 

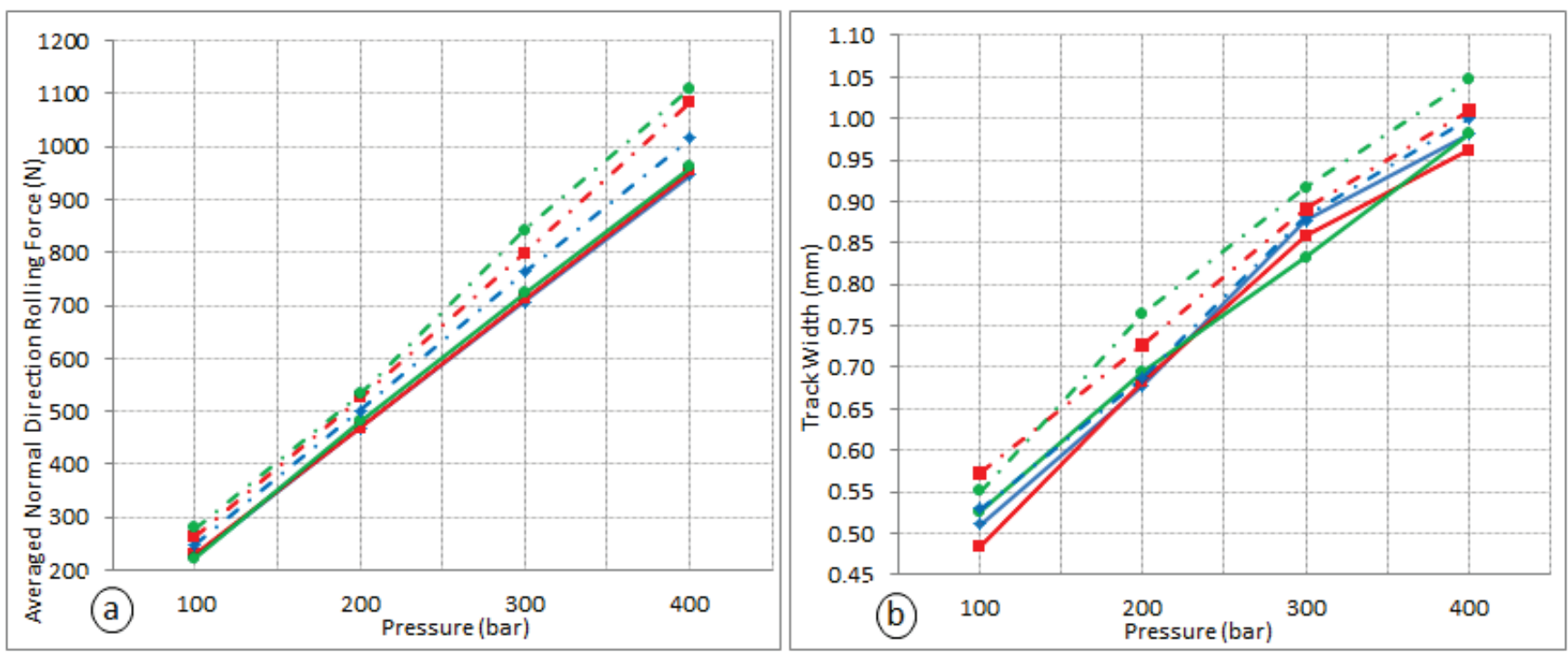

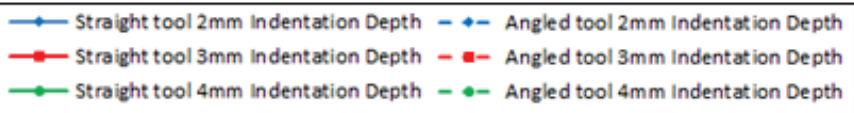

Fig. 3 Averaged normal direction rolling force (a) and track width (b)

The initial surface roughness Ra was $0.06 \mu \mathrm{m}$ in the longitudinal and $0.47 \mu \mathrm{m}$ in the transverse directions. The Ra measured after DCR is $0.02 \mu \mathrm{m}$ and it is identical in the longitudinal direction for varied pressure, indentation depth and tool type with a fixed overlap of $90 \%$. For transverse direction, the Ra for 400 and 200 bar pressures are $0.17 \mu \mathrm{m}$ and $0.09 \mu \mathrm{m}$ respectively with negligible effects from indentation depth and tool type.

The residual stress depth profile measured after DCR treatment in Fig. 4 and 5 shows transverse direction stresses were higher than the longitudinal direction. In Fig 5a, the maximum residual stresses for 200bar pressure are -780MPa in longitudinal and $-1060 \mathrm{MPa}$ in transverse directions and were measured at the depth of $100 \mu \mathrm{m}$ and $50 \mu \mathrm{m}$ respectively. In Fig. 5b, the maximum residual stresses for $400 \mathrm{bar}$ pressure are $-750 \mathrm{MPa}$ in longitudinal and $-1075 \mathrm{MPa}$ in transverse directions and were measured at the depth of $110 \mu \mathrm{m}$ and $100 \mu \mathrm{m}$ respectively. In Fig. 4 and 5, there is an increase in maximum compressive residual stress in transverse direction for the 200bar and 400bar pressure in an angled tool with high indentation depth compared to straight tool. In Fig 5b, there is an increase in the surface compressive residual stress in the transverse direction for 400bar pressure in an angled tool with high indentation depth compared to straight tool. It is observed that the maximum compressive residual stress profile for angled tool was shifted deeper into material depth due to the high rolling force as seen in Fig. 3a.

The increase in the surface and sub surface compressive residual stresses and the consistent surface roughness $\mathrm{Ra}$ are required to be further investigated with fatigue analysis, to evaluate the significance of high rolling force from the angled tool type with varied indentation depth. The influence of the angled tool design should be carefully studied using residual stress and force measurements for pressure greater than 400 bar or different ball diameter and the angle of the tool body, to investigate if high rolling force can cause cycle softening at the surface, leading to reduction in compressive residual stress which is detrimental to fatigue life. 

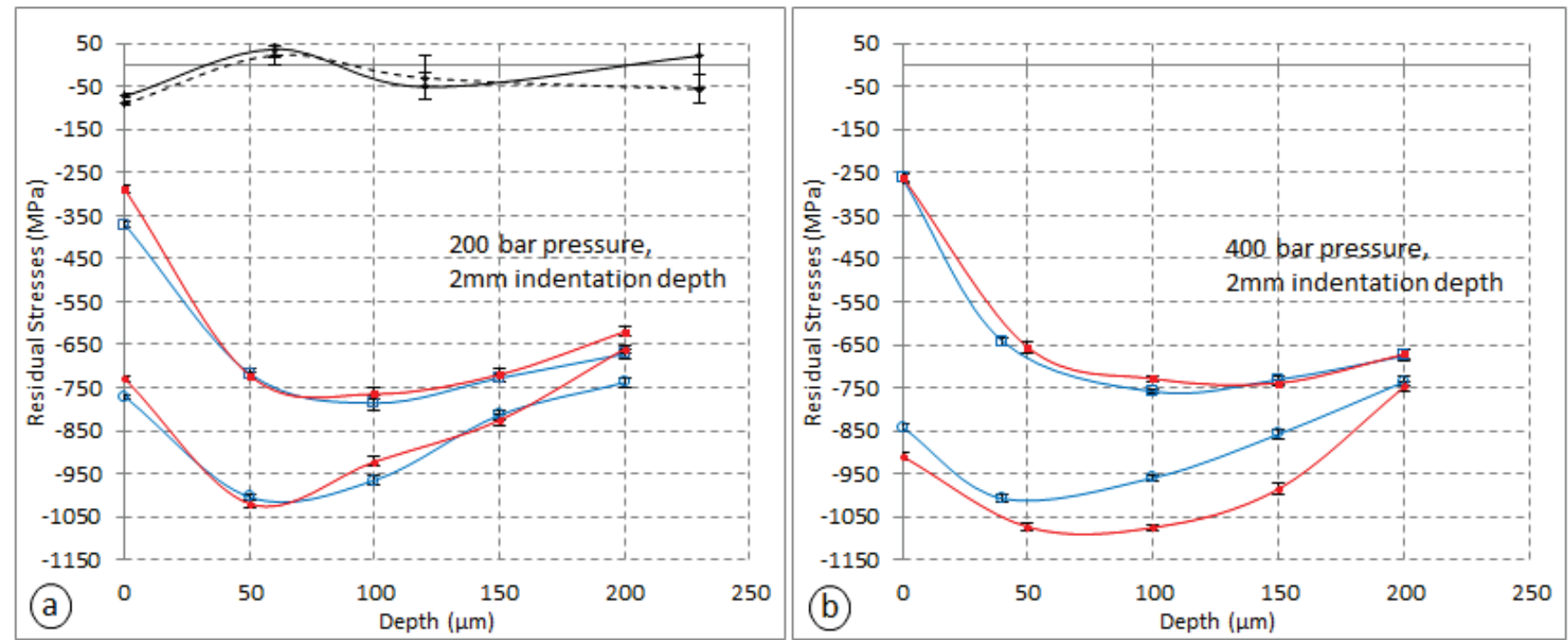

\begin{tabular}{|c|c|}
\hline$\square$-Straight tool(Longitudinal) & - - Straight tool (Transverse) \\
\hline$\rightarrow-$ Angled tool (Longtudinal) & $\longrightarrow$ Angled tool (Transverse) \\
\hline — Untr eated (Longtudinal) & - - - - Untr eated (Transverse) \\
\hline
\end{tabular}

Fig. 4 Residual stress depth profiles for 200bar pressure (a) and 400bar pressure (b) with $2 \mathrm{~mm}$ indentation depth
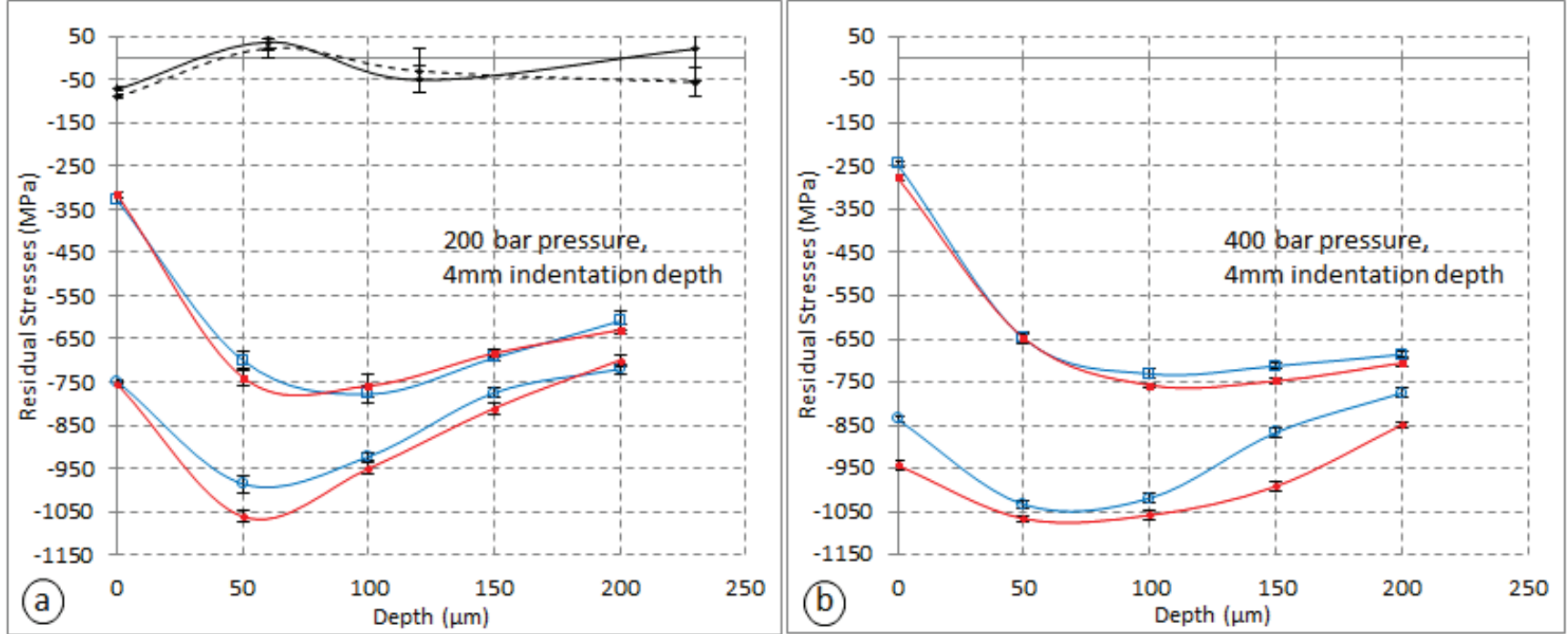

\begin{tabular}{|c|c|}
\hline - -Straight tool (Longitudinal) & $0-$ Straight tool (Transverse) \\
\hline- - Angled tool (Longtudinal) & $\longrightarrow$ Angled tool (Transverse) \\
\hline$\rightarrow$ Untr eated (Long tudinal) & --- - Untr eated (Transverse) \\
\hline
\end{tabular}

Fig. 5 Residual stress depth profiles for 200bar pressure (a) and 400bar pressure (b) with 4mm indentation depth

\section{Summary and conclusion}

DCR experimental trials were conducted using $\varnothing 6.3 \mathrm{~mm}$ ball diameter tool that has two variants, a straight and an angled tool design, to study the effects on the averaged normal direction rolling force, and residual stress depth profiles caused by the tool design and its indentation depth. In the track width and average rolling forces analysis, the angled tool caused higher track width for increasing indentation depth and rolling pressure corresponding with the high rolling force measured. Its effect 
on the residual stress depth profile is an increase in the surface compressive stress and maximum compressive stress for transverse direction using 400 bar pressure. The surface roughness Ra is not affected by the high rolling force. Fatigue analysis is proposed to study the influence of the increase in compressive residual stress profile using the angled tool design as a result of high rolling force with varied indentation depth.

\section{Acknowledgements}

The author would like to thank engineers Mr. Alex Goh Qi Ming, Mr Buenaventura Rizaldy Jr Tubera and Mr Jermin Soh Ming Jie who helped in the experiments and measurements, and show sincere appreciation to Mr. Stefan Zenk from Ecoroll AG Werkzeugtechnik for his technical guidance.

\section{References}

[1] I. Altenberger, U. Noster, B. L. Boyce, J. O. Peters, B. Scholtes, and R. O. Ritchie, "Effects of Mechanical Surface Treatment on Fatigue Failure in Ti-6Al-4V: Role of Residual Stresses and Foreign-Object Damage," Materials Science Forum, vol. 404-407. pp. 457-462, 2002. http://dx.doi.org/10.4028/www.scientific.net/MSF.404-407.457

[2] I. Altenberger, "Deep rolling-the past, the present and the future," in Proceedings of 9th international conference on shot peening, 2005, pp. 6-9.

[3] P. Juijerm and I. Altenberger, "Effective boundary of deep-rolling treatment and its correlation with residual stress stability of $\mathrm{Al}-\mathrm{Mg}-\mathrm{Mn}$ and $\mathrm{Al}-\mathrm{Mg}-\mathrm{Si}-\mathrm{Cu}$ alloys," Scripta Materialia, vol. 56, no. 9, pp. 745-748, 2007. http://dx.doi.org/10.1016/j.scriptamat.2007.01.021

[4] I. Altenberger, R. K. Nalla, Y. Sano, L. Wagner, and R. O. Ritchie, "On the effect of deeprolling and laser-peening on the stress-controlled low- and high-cycle fatigue behavior of Ti$6 \mathrm{Al}-4 \mathrm{~V}$ at elevated temperatures up to $550^{\circ} \mathrm{c},{ }^{\prime}$ International Journal of Fatigue, vol. 44. pp. 292-302, 2012. http://dx.doi.org/10.1016/j.ijfatigue.2012.03.008

[5] C. M. Gill, N. Fox, and P. J. Withers, "Shakedown of deep cold rolling residual stresses in titanium alloys," Journal of Physics D: Applied Physics, vol. 41, no. 17, p. 174005, 2008. http://dx.doi.org/10.1088/0022-3727/41/17/174005

[6] A. Rodríguez, L. N. López de Lacalle, A. Celaya, A. Lamikiz, and J. Albizuri, "Surface improvement of shafts by the deep ball-burnishing technique," Surface and Coatings Technology, vol. 206, no. 11-12. pp. 2817-2824, 2012. http://dx.doi.org/10.1016/j.surfcoat.2011.11.045

[7] A. M. Abrão, B. Denkena, B. Breidenstein, and T. Mörke, "Surface and subsurface alterations induced by deep rolling of hardened AISI 1060 steel," Production Engineering, vol. 8, no. 5, pp. 551-558, 2014. http://dx.doi.org/10.1007/s11740-014-0539-x

[8] M. Beghini, L. Bertini, B. D. Monelli, C. Santus, and M. Bandini, "Experimental parameter sensitivity analysis of residual stresses induced by deep rolling on 7075-T6 aluminium alloy," Surface and Coatings Technology, vol. 254. pp. 175-186, 2014.

http://dx.doi.org/10.1016/j.surfcoat.2014.06.008

[9] F. Klocke, V. Bäcker, H. Wegner, B. Feldhaus, H. U. Baron, and R. Hessert, "Influence of process and geometry parameters on the surface layer state after roller burnishing of IN718," Production Engineering, vol. 3, no. 4-5. pp. 391-399, 2009. http://dx.doi.org/10.1007/s11740-009-0182-0

[10] M. G. Moore and W. P. Evans, "Mathematical correction for stress in removed layers in X-ray diffraction residual stress analysis," SAE Technical Paper, 1958. 